\title{
Construction and Practice on University- Enterprise Collaborative Innovation and Talents Training's Dynamic Mechanism in Local Universities
}

\author{
Tao CHEN \\ School of Management \\ Wuhan University of Science and Technology \\ Wuhan, China \\ e-mail: 0503001@wust.edu.cn
}

\author{
Qiaohui XU \\ School of Management \\ Wuhan University of Science and Technology \\ Wuhan, China \\ e-mail: 1156412927@qq.com
}

\begin{abstract}
The educational practice of Domestic and overseas show that, it plays a key role in carrying out a high level of collaborative innovation between enterprise and university for maintaining the vitality of innovation and enhancing the competitiveness of enterprises, which also benefits for university innovation as well as the cultivation of high level talents. Therefore, we need to pay close attention to build university-enterprise collaborative innovation and talents training dynamic mechanism. For almost a decade, Wuhan University of Science and Technology (WUST for short) is industry service oriented, and actively builds a university-enterprise collaborative innovation and talent training platform, while promoting the formation of a new mechanism for talents training.
\end{abstract}

Keywords-industry oriented; university-enterprise collaborative innovation; dynamic mechanism; talent training platform; cooperative education concept

\section{INTRODUCTION}

In the modern world, innovation ability has become the core element of national competitiveness. "2011 plan" promoted by Ministry of Education clearly indicates that we should promote collaborative innovation actively, encouraging universities to carry out in-depth cooperation with scientific research institutions and enterprises through institutional innovation and policy project guidance, then, it will be helpful to establish the strategic alliance of collaborative innovation to promote the sharing of resources and jointly carry out major research project, which will make substantive achievements in key areas and strive to make a positive contribution to the innovative country [1].

In the past ten years, owing to the basic research and applied research resources of our country incline to the university, the initiative of university innovation has been greatly enhanced and knowledge innovation ability

upgrade quickly. However, since it has existed the fetter of policy and mechanism on the cooperation between

universities and enterprises, the so-called collaborative innovation of enterprises and colleges remain at a lower level at all time, which not only hinders the effective transfer of scientific and technological achievements in colleges, but also it limits the interests of enterprises and universities to participate in collaborative innovation as well [2].

International experience and domestic practice have shown that, it plays a key role in carrying out a high level of collaborative innovation between enterprise and university for maintaining the vitality of innovation and enhancing the competitiveness of enterprises, at the same time it highly benefits for university innovation as well as the cultivation of high level talents too. For example: Microsoft set up a joint laboratory with Tsinghua University, Bell do it with Shanghai JiaoTong University and Peking University as well, and so on.

It can be seen that the domestic colleges, including Hubei provincial key universities, make many efforts to carry out scientific and technological research as well as innovation actively, and it is gradually narrowing the gap with the international high-tech frontier as well. At present, the key is that it is urgently needed to be guided by the policy and market mechanisms, and promote the universities to conduct the depth and high level of collaborative innovation with enterprises and research institutions, by doing this, on the one hand, the university will get the latest research achievements continuously and industrialization rapidly, and enhance the competitiveness of enterprises in the international market; on the other hand, enterprises and universities will be increased in the depth of the integration of talents training, and the level of innovative talent training will be enhanced.

\section{RESEARCH ON THE DYNAMIC MECHANISM OF UNIVERSITY-ENTERPRISE COLLABORATIVE INNOVATION AND TALENTS TRAINING'S WITH INDUSTRY ORIENTED IN LOCAL UNIVERSITY}

\section{A. Local Universities in the Traditional Industry on the Relationship Changes of Dependence, Relying, Interdependence}

After the baptism of historical heritage and change, traditional universities affiliated with the Central Ministry go out different trajectories: A small number of colleges are directly into the Ministry of Education, as "985", "211" college, Such as Northeastern University and Beijing University of Technology originally belonged to the Ministry of Metallurgical Industry, Shanghai University of Finance and the Central University of Finance formerly Ministry of Finance; There are also a 
few colleges continue to be held by the Ministry, such as Huaqiao University directed by the Overseas Chinese Affairs Office of the State Council, South-Center University for Nationalities directed by State Ethnic Affairs Commission, and so on. At the same time, a large number of colleges delegate to local government, which are formerly belonged to the Ministry of Coal Industry, the Ministry of Petroleum Industry, the Ministry of Metallurgical Industry, the Ministry of Textile Industry, the Ministry of Chemical Industry, the Ministry of Commerce, the Ministry of Water Conservancy and Electric Power and so on, become the competent universities of local government. As Local universities in the traditional industry, there is no doubt that they need to serve for local regional economic development and make some contributions as a result of the long-term sheltered in the local government, however, due to various reasons, this universities have some distinctive characteristics of the industry, whether it is the subject of professional, or talent training, or even scientific research, it can hardly do without the connection of the industry enterprises. Therefore, when these unique colleges go through nearly 20 years of hesitation and painstaking pondering, they start with some early exploration, many of them gradually adapt and begin to integrate into the trend of the local and regional economic development positively, and it make some amazing contribution too.

However, they sometimes have to sink into the "two vain" situation of dependence and relying in this process: for one thing, since it shelter and rely on the local, they must focus on the requirements of the local economic and social development, identifying the demand point, exerting their advantages in talents training, scientific research and especially in the social service field, for another, due to the specialty of the subject and its tendency, they are inextricably linked with the industry enterprises, even as local university, they still prefer the traditional tied industry enterprises, by cooperating and collaborating and establishing a strategic alliance relationship with them to obtain the "source" and "ultimate goal" of innovative research, or practice based talent training, or funding support for sustainable development of the universities. Fortunately, some universities find out a valid path suitable for themselves in the process, and become the leader of the traditional industry in the local university during a period of time, such as Zhejiang University of Technology, WUST, Qingdao University of Science \& Technology, etc. But it must be noted that a considerable number of universities do not become the "lucky" in the face of local and industry enterprise, the two fronts can not parallel and converge and be in the embarrassing situation of " it can't touch the sky and the ground". Even some apparent successful college in a certain period of time, along with the changes and adjustment of industrial sectors, will sink into "lost" situation once again, and it will put these talents training and scientific research universities and social services into crisis.

\section{B. The Analysis of Enterprises Sources of Resistance in the University-enterprise Cooperative Innovation and Talent Development}

Even in the process of cooperation and close collaboration between universities and enterprises, it often has different perspectives of the two sides in talents training awareness and generates different levels of resistance from enterprises and universities. Through the research, it is not difficult to find that the resistance mainly comes from the following aspects:

First of all, viewed from the reality and immediate interests, there is a big difference on the mission and objectives between enterprises and universities. Enterprise or business leader primarily focus on the economic benefits ,the social benefits including social responsibility is neither a key indicator nor the non-mandatory requirements, especially while the pressure of enterprises economic benefits is relatively high, enterprise management is increasingly standardized and security requirements are increased, it is reasonable for enterprises to reject and deny the practice of students. But universities focus on long-term and future talents training, and pay more attention to social benefits and long-term interests. Undoubtedly, enterprises and universities have potential and practical contradictions in the mission and objectives.

Secondly, the change of supply and demand of talent market also makes enterprises, especially the central enterprises, state-owned enterprises and famous enterprises, to be less concerned about the ownership of talent, especially the problem of cooperation with local universities. From the shortage of college students to the basic balance between supply and demand of graduate students and even the relative surplus of the talent market, enterprises gradually raise the perspective for the sharp changes in the talent demand, no matter in the actual needs or face needs, enterprises gradually form a trend of excessive demand for talent. What's more, the concept of employment about modern college students have changed, growing numbers of them become the "waiting birds" and the frequency of job hopping is getting higher and higher. Relatively, the enterprise get less and less worried about the lack of ordinary university students, therefore, they do not pay much attention to the problem of cultivating talents in cooperation with universities.

Thirdly, it leads to the sharp increase of college students in the background of university enrollment expansion, a large number of student internships makes the enterprises, especially with large-scale, long process and the heavy equipment, bear great burden and security risks, this is one of the important reasons why quite a many enterprises are short of the motivation to accept college students practice.

Finally, another important factors of lacking enthusiasm and motivation are that industry enterprises are short of effective and feasible government policy guidance and support, from another angle of view, it also become the resistance of university-enterprise 
cooperation innovation and talents training.

Therefore, we need to eliminate enterprise resistance in university-enterprise collaboration and talent training, and learn successful experiences form domestic and international, then, exploring and forming the dynamic mechanism of university-enterprise collaboration and talents training as soon as possible, which is the key that local universities carry out university-enterprise collaborative innovation as well as talents training and form the endurance.

\section{Analysis on the Main Power and Public Policy of University-enterprise Collaborative Innovation and Talents Training in Local Universities}

If intended to form the mechanism of university-enterprise collaborative innovation and talents training, it is absolutely necessary to develop the driving force of the universities and enterprises. In the period of planned economy and the traditional mode of talents training, it mainly comes from external policies, plans and other forces, and also derives from the system of policy norms and resource allocation system. Under the environment of market economy, both the university and the enterprise, especially enterprises including state-owned enterprises, are lack of the institutional constraints of system and resources allocation, it change the relations of talent market supply and demand, and employment marketization as well as the diversification of talent flow, when the external policy constraints and resource allocation effect disappear, it is of vital importance that university and enterprise are jointly formed the internal dynamic mechanism of talent training. So no matter to the university or enterprise, how to make them generate the cooperative consciousness, and stimulate the driving force of innovation talents cultivation between them? According to the analysis of the development of higher education, economic development of the enterprise and the difference between the interests of the university and the enterprise, that is to say, it is critical to find mutual interests demands, to mining mutual intrinsic behavior motivation, to takes it as the starting point to carry out the analysis. Only in this way can we find the key to solve the problem.

Firstly, it needs the guidance of scientific policy and institution. In the current situation of supply and demand of talent market, the key to solve this problem is that we should start with enhancing the initiative of enterprise collaborative innovation and talents training. However, if we want to make enterprises involve in the cultivation of innovative talents proactively, we must use a series of economic and legal means. The ways including: hardening the policy requirements of industrial transformation, technological innovation and transformation on enterprise especially large state-owned enterprises, and prompting large enterprises and science and technology enterprises to increase the need for science and technology talents and achievements, then cooperating with the university positively and cultivating the talent to fulfill the need of enterprise reality and future development. In addition, it should formulate some systematic encouraging tax policies and related laws and regulations to encourage enterprises to cooperate with universities in carrying out talents training actively, and complement some soft constraints, such as corporate social responsibility obligations. Meanwhile, for the universities, it gradually makes them increase the efforts to university-enterprise collaborative innovation and talents training. Which includes the enormous changes in the graduate employment market situation, the undergraduate teaching audited assessment as well as professional certification of "five in one" construction of quality assurance system, the "2011 plan" as well as "excellent engineer" education program of national and provincial and other talents training reform requirements.

Secondly, it is necessary to change the concept of university and enterprise. As the talent operation is market-oriented, companies are no longer just staring at the individual universities, the sources of talents they need is diversified. As for the universities, the whereabouts of the graduate students also show a diversification. Therefore, the traditional single, one-way and relatively narrow supply and demand has been an unprecedented change. In this context, the two sides should change their ideas and strengthen communications, and it will gradually form collaborative education and cultivate needed talent together under the guidance of the market mechanism. In this concept, the two sides need to form an effective cooperative channel to form the mechanism of collaborative innovation and talents training by establishing a two-way communication link between university and enterprise, and then seek a win-win future.

Thirdly, it needs model optimization and system changes. Suited to the previous policies and concepts, the mode of talent training in universities needs to optimize and most universities are not to train "saints" students in the Den any more, but pay more attention to "the wave" for enterprise actual changes. The talents training objectives, programs and teaching all need to adapt to the changes in business and social-economic development, and then put the continuous development of the enterprise production, management mode, new technologies and new management methods into the teaching research, and make further deepen as well as improve in theory. At the same time, teaching and its management mechanism also adapt to the new change of the talent training mode. Hence, for adapting to this change, education management system should reform and adjust basically from top to bottom of the administrative style. It generally include: most of the local universities could gradually integrate with enterprise economic, and allow the social institutions and enterprises with strong sense of social responsibility to intervene in the development planning of university and decision-making on major issues through a variety of ways; the main discipline as well as specialty construction and talents training support in the local universities should be based on the regional economy and the actual development of enterprises, and 
adapt to the changes and make timely adjustment.

\section{The CONCEPT CONSTRUCTION AND Mechanism EXPLORATION OF THE SCHOOL-ENTERPRISE COLLABORATIVE INNOVATION AND TALENTS TRAINING}

A. Advocate the Concept of "Respect the Actual", and Practice the Concept of University-enterprise Collaborative Innovation and Talents Training and Education Cooperation with the Core of "Respect the Actual and Remove the Vanity"

WUST originally developed from Hubei Technological School started by Zhang Zhidong in Wuchang in 1898, it advocated the excellent style with "be quiet and studious, respect the actual and remove the vanity ", and eventually formed the four schooling belief of "face the industrial demand, cultivate the practical talents, advocate the learning style of respecting the actual and strengthen the practical training". For hundreds of years, the university has inherited and developed the tradition of "respect the actual", highlighted the advantages of the subject of iron and steel metallurgy, consistently cultivated the urgently needed talent of the metallurgy industry enterprises through university-enterprise collaborative activities [3].

In order to strengthen the teachers and students to understand the importance of university-enterprise cooperation, and make it become the common education concept of them. University carry out the industry education oriented towards "respect the actual" partly through the "one main line" and seizing the "three stage", and let many of teachers and students influence by university-enterprise cooperation tradition every hour and moment. On the other hand, it should encourage the teachers and students to participate in all kinds of university-enterprise collaborative activities actively through policy guidance and institutional norms, from that they could really feel the benefits of university-enterprise collaboration, thus, it will lay the foundation to the ideology of the university-enterprise cooperation as well as talents training and cultural quality.

\section{B. Construct the "Double-power" Mechanism which is \\ Industry Leading as well as Academic Excellence \\ Oriented and University-enterprise Collaborative \\ Talents Training.}

With industry leading and efficiency improvement as the driving force, establishing the new mechanism of the depth integration of enterprises and universities.

In order to solve the problem that business institutions lack of motivation in university-enterprise collaborative talents training fundamentally, the university should rely on the advantaged discipline combined with industry tightly , and combine with large and medium-sized backbone enterprises, such as Wuhan Iron and Steel ( Group ) Corp (WISCO for short), Guangzhou Iron and steel( Group ) Corp, and so on. Then, setting up the development and application platform of multi-disciplinary integration, multi-team collaboration and multi-technology integration.

Besides, in order to establish the leading position of WISCO R \& D and production in the domestic industry further, in December 2007, it jointly declare and construct silicon steel of National Engineering Research Centers which takes WISCO as the main body and combines with WUST as well as other relevant universities. After three years of trial operation, it develops 8 standards and gets 21 patents, and eventually settles in WISCO in 2011 [4].

With quality improvement and academic excellence as the guidance, building the mechanism of university-enterprise collaborative innovation and talents training.

For the shortcoming of innovative spirit and ability training, it is mainly oriented towards quality improvement and academic excellence, and makes efforts to form the power to promote the innovation ability and the quality of talents training in the university, meanwhile, promoting university-enterprise collaborative innovation and talents training through the reform of the institutional mechanism and the promotion of teaching and scientific research policy.

In 2009, the university approved to become the innovation experimentation area of national talent training model. In 2010, it implement the strategic emerging (pillar) industry plan, which implement a year of general education and three years of professional education on the education mode, and use three years teaching theory and one year engineering practice of teaching model in the curriculum. Beginning in 2011, the university implement " the Training Program of Excellence Engineer Education ", and use the dual tutorial system, university teachers and business mentors jointly guide to theoretical study and engineering practice of the students.

\section{The Attempt and Exploration on Constructing the Talent Training Platform of University-enterprise Synergy and Deep Integration}

With the needs of industry interests as a link, and establishing a comprehensive strategic partnership with WISCO and other industries

Since 2007, the university has signed a comprehensive strategic cooperation agreement with nearly 20 large enterprises, which including the Guangzhou Iron and Steel Group, China Steel Group, Hubei Xinye steel, Xiangtan Steel. Besides, we has established a deep integration of university-enterprise cooperation relationship with WISCO which is the leading enterprises in China's iron and steel industry. The two sides set up Industry-University Cooperative and Advancing Committee that appoints general manager of WISCO as director, and sets up Joint Academic Committee that appoint double hired academician of WISCO and WUST as director.

University-enterprise jointly establish " the New Technology Research Institute of iron and steel of WISCO and WUST " as the platform of 
university-enterprise collaborative innovation and talents training. The Institute appoint headmaster of WUST as president, the office is located in the university and equipped with a full-time executive vice president. It's aimed to coordinate the strength of the university and the enterprise, to carry out strategic cooperation, new technology development as well as innovation and talents training as well as reserves, etc.

As is the major demand of industry enterprises oriented, and leading the major technology projects to promote university-enterprise collaboration research and innovation

Jointly Building "the joint laboratory of WUST and WISCO", high-performance steel material and its application in Hubei province collaborative innovation center. Both sides follow the guiding ideology of "co-construction and co-management, cross-gathering, leading innovation and supporting development", Aiming at the strategic demand of the state and the development demand of WISCO, developing the leading edge technology and key products of metallurgical industry to build a scientific research platform "the joint laboratory of WUST and WISCO" together . For building it, WISCO invest 20 million yuan for two years, WUST construct research building and experimental factory in its campus of QingShan, meanwhile, it provide matching funds 10 million yuan in two years. By June 2016, the joint laboratory building has been basically completed.

\section{INSPIRATION AND REFLECTION}

As is seen from theoretical research and the practice of universities, although some of the local colleges of university-enterprise cooperative innovation and talents training has some foundation, which including the Ministry of Education to promote the "excellent plan" of talent training project, it further stress on the necessity of university-enterprise cooperation innovation as well as the applicable talents and enforceable path, It is undeniable that university-enterprise cooperatively develop talents training in domestic local universities, either from theory or from practice are facing many bottlenecks and resistance, it urgently need to find a solution basically. It can be found in the study that, how to establish the dynamic mechanism of enterprise collaborative innovation and talents training, and forming the internal driving force of the two sides especially the enterprise in the process, is still a key issue worthy of attention.

Therefore, as the universities directed by the local government and related institutions, it is necessary to create the necessary policy environment for the university-enterprise of local colleges in carrying out talents training work cooperatively, in addition, relieving the concerns and doubts of local enterprises including state-owned, private and foreign enterprises, and making them participate in the talents training of local colleges actively from the economic and social benefits and other aspects, and finally becoming the inner needs of enterprises.

\section{ACKNOWLEDGMENT}

This research was financially supported by Teaching research projects of Hubei Province(No: 2013219) and science and technology support project focused on Soft Science in Hubei province(No.: 2015BDF006).

\section{REFERENCE}

[1] Ministry of education.2011 collaborative innovation center construction and development planning [EB/OL] http://kaoyan. eol.cn/ zheng_ce_bian_hua_3936/.20140506/t20140506_1109511.shtml.

[2] Xiaohua Zong, Yinxing Hong. The innovation paradigm transformation and the deepening of the cooperative innovation mechanism of Chinese universities and enterprises[J]. higher education research, 2013 (7): 1-9.

[3] Mingchang He. Journal of Wuhan University of Science and Technology [M]. Beijing: Metallurgical Industry Press, 2008.

[4] Tao Chen, Liangcai Zeng etc. Based on stakeholder perspective collaborative research innovation [J]. Wuhan University of Science and Technology Journal (Social Science Edition), 2012, 14 (3): 341-344. 